\title{
BMJ Open Compliance to secondary prevention strategies for coronary artery disease: a hospital-based cross-sectional survey from Ernakulam, South India
}

\author{
Remya Sudevan (D) , ${ }^{1}$ Damodaran Vasudevan, ${ }^{2}$ Manu Raj, ${ }^{3}$ Rajesh Thachathodiyl, ${ }^{4}$ \\ Maniyal Vijayakumar, ${ }^{4}$ Jabir Abdullakutty, ${ }^{5}$ Paul Thomas, ${ }^{6}$ Vijo George, ${ }^{6}$ \\ Conrad Kabali ${ }^{7}$
}

To cite: Sudevan $\mathrm{R}$, Vasudevan D, Raj M, et al. Compliance to secondary prevention strategies for coronary artery disease: a hospital-based cross-sectional survey from Ernakulam, South India. BMJ Open 2020;10:e037618. doi:10.1136/ bmjopen-2020-037618

- Prepublication history and additional material for this paper are available online. To view these files, please visit the journal online (http://dx.doi. org/10.1136/bmjopen-2020037618).

Received 10 February 2020 Revised 24 August 2020 Accepted 10 September 2020

Check for updates

(C) Author(s) (or their employer(s)) 2020. Re-use permitted under CC BY-NC. No commercial re-use. See rights and permissions. Published by BMJ.

For numbered affiliations see end of article.

Correspondence to Dr Remya Sudevan; drremyasudevan27@gmail.com

\section{ABSTRACT}

Objectives The primary objective of the study was to report the compliance to secondary prevention strategies for coronary artery disease (CAD), such as smoking cessation, weight management, low-density lipoprotein (LDL) cholesterol control, blood pressure control, glycaemic control, physical activity and cardiovascular drug therapy from a resource-limited setting.

Design Analytical cross-sectional survey with data collection using questionnaire administered by study personnel.

Setting Institutional-two tertiary care hospitals and two cardiology clinics.

Participants Patients in the age group of 30-80 years with documented CAD with a minimum of 1 year and a maximum of 6 years of follow-up after diagnosis.

Main outcome measures The main outcome measures were the prevalence of individual compliance to secondary prevention strategies for CAD such as smoking cessation, weight management, LDL cholesterol control, blood pressure control, glycaemic control, physical activity and cardiovascular drug therapy. The secondary outcomes were the association of secondary prevention strategies with age, sex, domicile, socioeconomic status, insurance and type of treatment.

Results We recruited a total of 1206 patients among whom 879 (72.9\%) were males. The median age of patients was 62 (14) years. The compliance to smoking cessation was $93.86 \%$ (95\% Cl 91.66\% to $96.06 \%$ ), ideal body mass index was $63.76 \%(95 \% \mathrm{Cl} 61.05 \%$ to $66.47 \%)$, blood pressure control was $65.11 \%(95 \% \mathrm{Cl}$ $62.42 \%$ to $67.80 \%)$, LDL compliance was $36.50 \%(95 \%$ Cl $33.18 \%$ to $39.82 \%$ ), diabetes control was $51.23 \%$ (95\% Cl $46.10 \%$ to $56.36 \%$ ) and adequate physical activity was $39.22 \%$ (95\% Cl 36.46\% to $41.98 \%$ )respectively. Reported compliance for cardiovascular drugs therapy was $96 \%$ for antiplatelets, $89.4 \%$ for statins, $68.2 \%$ for beta blockers, $37.7 \%$ for renin angiotensin aldosterone system blockers, $81.28 \%$ for oral hypoglycaemic agents and $22 \%$ for insulin therapy.

Conclusion Compliance to secondary prevention strategies for $C A D$ in resource limited settings are moderate. This needs further improvement for better outcomes related to CAD in future.

\section{Strengths and limitations of this study}

- The study has a large sample size.

- There was a high response rate among responders during recruitment.

- The study presents information related to several confounders which were used in the final analysis.

- The study has limited geographic/ethnic variation among study subjects.

- There is a probability of social desirability bias from patient responders in the study.

\section{INTRODUCTION}

Non-communicable diseases (NCDs) have surpassed communicable diseases in terms of overall burden of diseases as well as its resultant consequences globally due to epidemiological transition. ${ }^{1}$ Among the NCDs, cardiovascular diseases have emerged as the major contributor to mortality and morbidity. ${ }^{2}$ Among cardiovascular diseases, the major share of mortality arises from coronary artery diseases (CADs). ${ }^{2}$ Cardiovascular diseases together contributed to 17.3 million deaths in 2013, a significant leap from the 12.3 million deaths reported from the same category of diseases in $1990 .{ }^{2}$ The number of deaths attributed to ischaemic heart diseases (IHDs) increased from 7.96 million in 2006 to 9.48 million deaths in $2016 .^{3}$ Even though CAD mortality has declined in developed nations, India is having a remarkable rise in the morbidity and mortality associated with CAD. ${ }^{4}$ Studies have shown that Indians are more vulnerable to $\mathrm{CAD}$ and exhibit higher mortality compared with western population. $^{15-7}$

Despite advances in pharmacological and invasive treatment methods, risk factors remain independent predictors of cardiovascular mortality in patients with $\mathrm{CAD}^{8}$ 
Evidences have proved the beneficial effects like decline in cardiac re-events, mortality and improved quality of life in patients with CAD by secondary prevention through comprehensive risk factor modification. ${ }^{9}$ The modifiable risk factors for secondary prevention of CAD are multifactorial and are governed by specific domains such as health policy, health system intervention, health promotion and quality improvement programmes. ${ }^{1}$ Structured guidelines that are evidence-based and complimented by stratification of benefit levels are available for secondary prevention of CAD. ${ }^{10}{ }^{11}$ An ideal strategy would include focusing on nine risk reduction options. These include blood pressure control, lipid management, management of type 2 diabetes mellitus, weight management, adequate physical activity (PA), cessation of smoking, identification and management of depression, appropriate use of cardiovascular drugs and cardiac rehabilitation. $^{1011}$

The overall benefit for the patient under treatment for CAD is often suboptimal due to poor implementation of secondary prevention strategies across the world and especially in South Asia. ${ }^{12-17}$ The EUROASPIRE V study underlines the missed opportunity of secondary prevention of CAD in several countries in Europe. ${ }^{17}$ This study shows that among patientswith a clinical diagnosis of CAD, $19 \%$ still remained as smokers, $38 \%$ remained obese, $59 \%$ remained centrally obese, $48 \%$ had a blood pressure $\geq 140 / 90 \mathrm{~mm} \mathrm{Hg}(\geq 130 / 80$ in people with diabetes mellitus), $71 \%$ had a serum total cholesterol $\geq 70 \mathrm{mg} / \mathrm{dL}$, $29 \%$ reported being diabetic and only $54 \%$ among them had good diabetic control as represented by a glycated haemoglobin level of $<6.5 \%$ at a median follow-up of 1.1 years. ${ }^{17}$

The cardiovascular disease (CVD) risk factor profile of the state of Kerala, India suggests that the state is in for a massive epidemic of CAD in the coming decades. The overall age-adjusted prevalence of definite CAD reported from the state by Krishnan et $\mathrm{al}^{18}$ was $3.5 \%$ while the prevalence of any CAD was $12.5 \%$. The study also reported a high prevalence of CVD risk factors like diabetes $(33.30 \%)$, hypertension $(51.32 \%)$, high total cholesterol $(41.01 \%)$, low levels of high-density lipoprotein $(42.76 \%)$, physical inactivity $(31.02 \%)$ and family history of CAD (25.29\%). ${ }^{18}$ There is deficiency of published data related to secondary prevention of CAD from the state of Kerala.

The primary objective of the present study was to estimate the proportion of patients with documented CAD who report compliance in a hospital setting to recommended ideal secondary prevention options for weight management, blood pressure control, lipid management, diabetes control, cardiovascular drug therapy, smoking cessation and PA. The secondary objective was to examine the association between individual prevention strategies with selected parameters including (1) age, (2) sex (3) socioeconomic status, (4) place of domicile, (5) insurance and (6) type of treatment for CAD.

\section{MATERIALS AND METHODS}

\section{Selection and description of study participants}

The study was conducted in two hospitals and two cardiology clinics in Ernakulam district, Kerala state. The study was coordinated by Amrita Institute of Medical Sciences and Research Centre, Kochi, Kerala, India. The period of study was 24 months (January 2017-January 2019). The study design was an analytical cross-sectional survey.

We used the study by Kotseva et $a l^{19}$ to calculate the sample size. The Euroaspire study reported a compliance of $19.5 \%$ for low-density lipoprotein (LDL) target $(<70$ $\mathrm{mg} / \mathrm{dL}$ ) in accordance with the guidelines published by the Joint European Society guidelines. ${ }^{20}$ We used the LDL target to compute the sample size as this was the target applicable to all patients. The minimum sample size required was 683 with a desired CI of $95 \%$ and $3 \%$ absolute precision. We inflated the sample size to 1200 to adjust for withdrawals from the study.

Patients with documented $\mathrm{CAD}$ were recruited by consecutive sampling from the patients under care at the study institutions. We defined CAD as per Sheridan and Crossman review. ${ }^{21}$

The inclusion criteria were (1) documented patients with $\mathrm{CAD}$ with minimum follow-up period of 1 year at the time of enrolment, (2) age group 30-80 years, (3) residing in Ernakulam district and (4) patients who could comprehend Malayalam or English. The exclusion criteria included (1) patients with a follow-up period of more than 6 years after CAD diagnosis at the time of enrolment and (2) subjects with concomitant illnesses like malignancy, stroke end-stage chronic kidney disease and chronic liver failure.

\section{Patient and public involvement}

Patients and the public were not specifically involved in the planning and execution of this study.

We plan to disseminate the study findings through patient support groups to improve the compliance to secondary prevention strategies.

\section{Study tool}

The study used a structured questionnaire which collected information under eight domains including (1) basic information and demographic details, (2) clinical history, comorbidities and habits, (3) details of primary event, (4) physical examination details, (5) biochemical assessment details, (6) details of current cardiovascular medications, (7) details of antidiabetic medications and (8) details of self-reported PA.

We defined compliance to the six individual secondary prevention strategies for CAD using the goals suggested in the guidelines of the European Society of Cardiology published in 2016. ${ }^{11}$ We used the WHO BMI classification to define compliance to target body mass index (BMI). ${ }^{22}$ The cut-offs used for defining compliance is presented as online supplemental appendix 1. We used the Kuppuswamy's socioeconomic scale (2018) for classifying the socioeconomic status of the study participants. ${ }^{23}$ 
The socioeconomic status (SES) was classified into low $(\leq 10)$, middle (11-25) and high (26-29) using the scores derived from this scale.

The first draft version was prepared after several consultations with all investigators (cardiologists and epidemiology consultants). This version of the questionnaire was prepared in English and tested in a subset of 50 patients who attended the cardiology outpatient department of the study institution. The same was revised by removing redundant questions and modifying several questions as per patient feedback on completion of this set of 50 patients. The revised version was approved by all investigators involved in the study. The English version was then translated to Malayalam and back translated to English by two separate language experts. The original English version and the back translated version were compared for concurrence and necessary modifications were done in consensus with all investigators. The patients were given the option of being interviewed in English or Malayalam for ease of data collection. All interviews were done by study personnel who were trained by the principal investigator before the commencement of data collection. The study questionnaire was administered by the study personnel in view of the multiple sections which required technical data capture from diagnostic reports, discharge summaries and prescriptions. The English version of the study tool used is presented as online supplemental appendix 2. The tool administrations were conducted in-hospital/clinic for enroled patients.

\section{Statistical analysis}

Statistical analyses were conducted using SAS V.9.4 for Windows (SAS Institute, Cary, North Carolina, USA). The descriptive analysis was done to characterise the study population. Categorical variables are summarised as proportions whereas continuous variables are summarised as medians (Q1-Q3). We used the ShapiroWilk test to examine the distribution of data. We used the modified Poisson model to estimate the adjusted prevalence ratios for the following outcomes: current smoking, high LDL, high HbA1c, high systolic blood pressure, low PA and high BMI. A separate model was fitted for each outcome. Each model included the following six predictors: age, sex, place of domicile, SES, insurance status and type of CAD treatment taken. The prevalence ratios are presented with their 95\% CIs. The regression coefficients were tested using the Wald statistic. We used the Bonferroni correction to account for multiple comparisons in the subgroup analysis and a threshold of 0.008 was used for testing significance of associations.

\section{Ethical approval}

The study was approved by the institutional ethics committee (IRB-AIMS-2017-125). Written informed consent was obtained from study participants before collecting the data. The consent included title, purpose, methods, benefits and right to withdraw from the study at any point of time. Confidentiality was maintained throughout the study.

\section{RESULTS}

\section{Baseline data}

We approached 1230 patients who were eligible for recruitment as part of the study. A total of 1206 patients provided consent and participated in the study giving us a response rate of $98 \%$. The final analysis included data from 1206 patients with CAD who were under follow-up from the four study centres. The baseline details of the study population are presented as table 1 . The STROBE flowchart is presented as figure 1 .

Among patients, $879(72.9 \%)$ were males and 767 $(63.6 \%)$ were from rural areas. In the study, the majority of patients were in the age group of 61-80 $(647,53.6 \%)$ years. The median age of the participants was 62.0 (14.0) years. The median age for males and females were 61.0 (15.0) and 65.0 (14.0) years, respectively. The overall median age at occurrence of primary event was 59.0 (14.0) years. The median age at occurrence of primary event for males and females were 58.0 (14.0) and 61.0 (14.0) years, respectively. The median follow-up was 2.0 (3.0) years.

\section{Overall compliance to secondary prevention strategies}

The overall compliance among patients with documented CAD for the seven individual secondary prevention strategies mentioned earlier is presented as tables 2 and 3 .

Among 456 patients who reported smoking at the time of event, 428 (93.86\%, 95\% CI 91.66 to 96.06) quit smoking and were reported to be non-smoking at the time of follow-up evaluation. An ideal BMI $(\geq 18.5$ to $\left.<25 \mathrm{~kg} / \mathrm{m}^{2}\right)$ was seen in $769(63.76 \%, 95 \%$ CI 61.05 to 66.47$)$ patients. Similarly, adequate blood pressure control $(<140 / 90)$ was seen among $785(65.11 \%, 95 \%$ CI 62.42 to 67.80$)$ patients at follow-up. Only $810(67.16 \%)$ patients reported checking their LDL cholesterol within 6 months of the time of assessment. Among them, only 296 (36.50\%, 95\% CI 33.18 to 39.82) were compliant to the target recommended (<70 mg/dL). Among 609 (50.5\%) patients who were diabetic at the time of event, HbAlc was measured within 3 months in 365 (59.93\%) patients. In this subset of patients with diabetes, only 187 (51.23\%, 95\% CI 46.10 to 56.36) reported compliance to adequate diabetes control (HbA1c $<7 \mathrm{mg} \%)$. Adequate PA $(\geq 150$ $\mathrm{min} /$ week of moderate to vigorous PA) was reported by 473 (39.22\%, 95\% CI 36.46 to 41.98$)$ patients in the study.

\section{Compliance to cardiovascular drug therapy in the study population}

Among study patients antiplatelets were prescribed for 1158 (96\%), statins for 1078 (89.4\%), beta blockers for $822(68.2 \%)$, renin angiotensin aldosterone system (RAAS) for $455(37.7 \%)$, calcium channel blockers for $215(17.8 \%)$ and diuretics for $147(12.2 \%)$. The details as well as the sex-stratified prescription percentages are 
Table 1 Baseline characteristics of study population

\begin{tabular}{|c|c|c|c|c|}
\hline & Variables & Overall n (\%) & Male n (\%) & Female $\mathrm{n}(\%)$ \\
\hline & Overall & $1206(100)$ & $879(72.9)$ & $327(27.1)$ \\
\hline \multirow[t]{3}{*}{1} & Place of residence & & & \\
\hline & Urban & $439(36.4)$ & $313(35.6)$ & $126(38.5)$ \\
\hline & Rural & $767(63.6)$ & $566(64.4)$ & $201(61.5)$ \\
\hline \multirow[t]{4}{*}{2} & SES & & & \\
\hline & High & $44(3.6)$ & $37(4.2)$ & $7(2.1)$ \\
\hline & Middle & $742(61.5)$ & $582(66.2)$ & $160(48.9)$ \\
\hline & Low & $420(34.8)$ & $260(29.6)$ & $160(48.9)$ \\
\hline \multirow[t]{7}{*}{3} & Insurance & & & \\
\hline & Yes & $436(36.2)$ & $313(35.6)$ & $123(37.8)$ \\
\hline & Type of insurance & & & \\
\hline & Self public & $128(10.6)$ & $101(11.5)$ & $27(8.3)$ \\
\hline & Self private & $82(6.8)$ & $58(6.6)$ & $24(7.4)$ \\
\hline & Self employer provided & $19(1.6)$ & $17(1.9)$ & $2(0.6)$ \\
\hline & Covered by family plans of children & $207(17.2)$ & $137(15.6)$ & $70(21.5)$ \\
\hline \multirow[t]{7}{*}{4} & Comorbidities & & & \\
\hline & Family history of CAD & $497(41.2)$ & $356(40.5)$ & $141(43.1)$ \\
\hline & Hypertension & $637(52.8)$ & $427(48.6)$ & $210(64.2)$ \\
\hline & Diabetes & $609(50.5)$ & $432(49.1)$ & $177(54.1)$ \\
\hline & Dyslipidaemia & $544(45.1)$ & $374(42.6)$ & $170(52)$ \\
\hline & Smoking & $28(2.3)$ & $28(3.2)$ & 0 \\
\hline & Alcohol intake & $93(7.7)$ & $84(9.6)$ & $9(2.8)$ \\
\hline \multirow[t]{5}{*}{5} & CAD subtypes & & & \\
\hline & STEMI & $379(31.4)$ & $285(32.4)$ & $94(28.7)$ \\
\hline & NSTEMI & $285(23.6)$ & 210 (23.9) & 75 (22.9) \\
\hline & Unstable angina & $258(21.4)$ & $192(21.8)$ & $66(20.2)$ \\
\hline & Effort angina & $284(23.5)$ & $192(21.8)$ & $92(28.1)$ \\
\hline \multirow[t]{4}{*}{6} & Treatment taken & & & \\
\hline & Medical therapy alone & $357(29.7)$ & $211(24.1)$ & $146(44.8)$ \\
\hline & Angioplasty & $679(56.3)$ & $527(60.1)$ & $152(46.6)$ \\
\hline & CABG & $170(14.1)$ & $141(16.0)$ & $29(8.9)$ \\
\hline
\end{tabular}

CABG, coronary arteries bypass graft; CAD, coronary artery disease; NSTEMI, non-ST elevation myocardial infarction; SES, socioeconomic status; STEMI, ST elevation myocardial infarction.

presented as table 3. Among 609 patients with diabetes, $495(81.28 \%)$ were on oral hypoglycaemic drugs and 134 (22\%) were on insulin therapy.

\section{Subgroup analysis: compliance profile stratified by selected variables}

We did a subgroup analysis of the study sample using subgroups based on selected variables including age, sex, SES, place of domicile, insurance and type of treatment taken. The adjusted prevalence ratios along with $95 \%$ CI for the same are presented as table 4 .

The associations are reported using adjusted prevalence ratios (Adj.PR) . Age showed a significant association with blood pressure (BP) control (Adj.PR 1.12, 95\% CI 1.03 to
1.21, $\mathrm{p}=0.005$ ) and PA (Adj.PR 1.36, 95\% CI 1.18 to 1.57, $\mathrm{p}<0.001)$ in the form of older patients reporting better compliance to both. Sex showed a significant association with smoking cessation and PA. Female patients reported better compliance to smoking cessation (Adj.PR 1.06, 95\% CI 1.02 to $1.10, \mathrm{p} 0.002$ ) and lower compliance to PA (Adj.PR 0.49, 95\% CI 0.39 to 0.62, $\mathrm{p}<0.001$ ) compared with male patients.

SES showed a significant association with prevalence of LDL control and PA. Patients from medium SES showed lower compliance to LDL target (Adj.PR 0.78, 95\% CI 0.71 to $0.86, \mathrm{p}<0.001$ ) and better compliance to PA targets (Adj.PR 1.38, 95\% CI 1.15 to $1.66, \mathrm{p}<0.001$ ) compared 


\section{STROBE FLOW CHART}
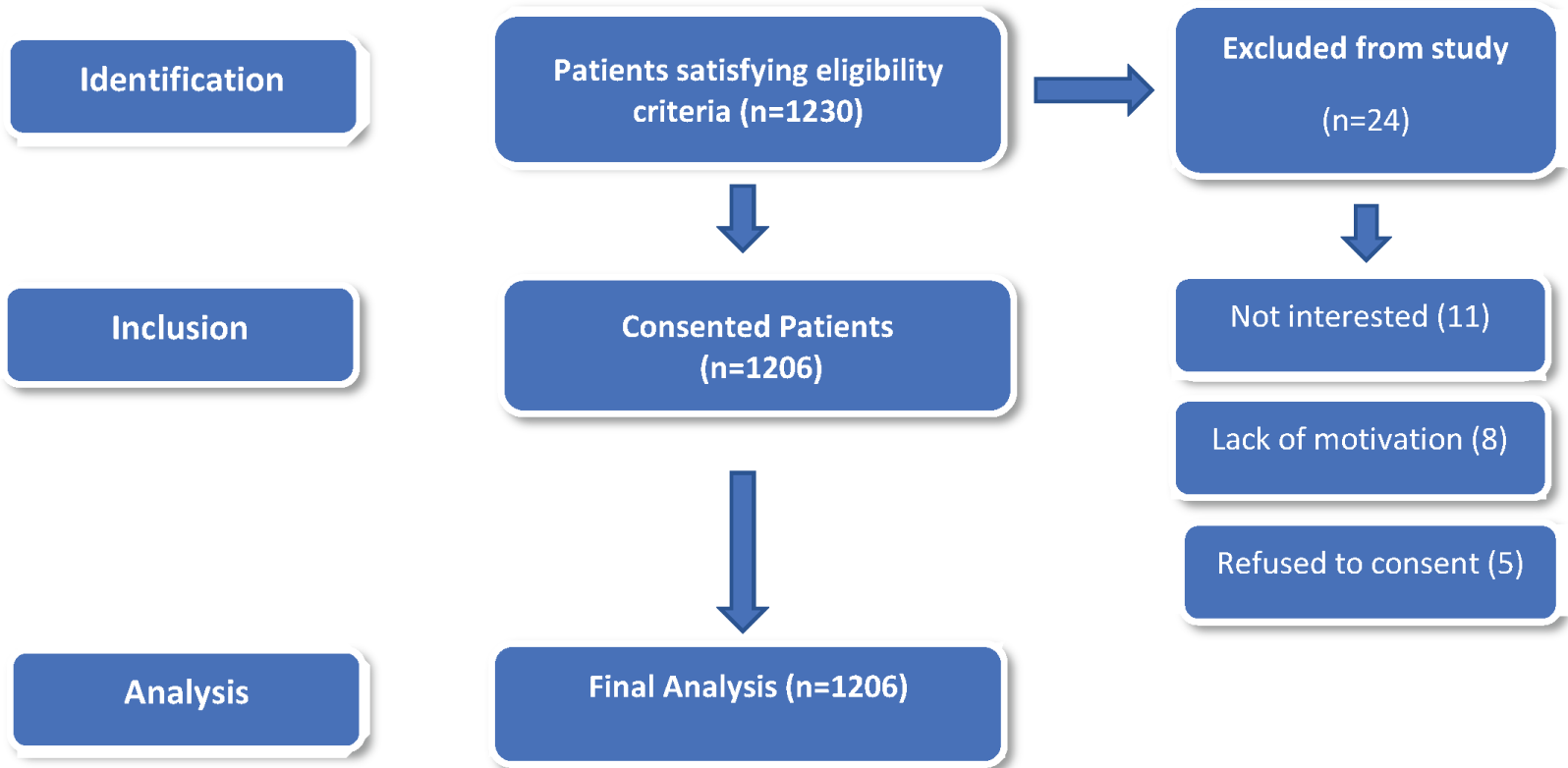

Consented Patients (n=1206)

Not interested (11)

Lack of motivation (8)
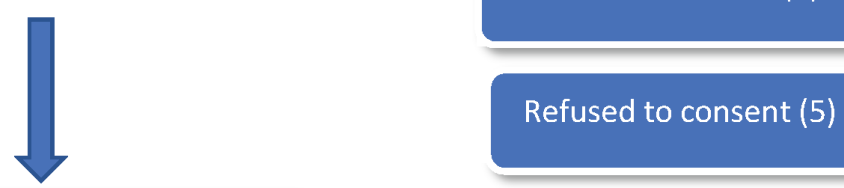

Refused to consent (5)

Final Analysis ( $n=1206$ )

Figure 1 STROBE flowchart.

with those from low SES. Insurance status showed a significant association with LDL control (Adj.PR 1.22, 95\% CI 1.11 to $1.34, \mathrm{p}<0.001)$ with those insured showing better compliance to this target. The type of treatment as well as place of domicile showed no significant association with any of the variables tested in the subgroup analysis.

\section{DISCUSSION}

The current study is probably the first of its kind from India looking at the compliance to accepted secondary prevention strategies among patients with documented CAD. The state of Kerala, in India is known to be the forerunner in most health indices for the country. ${ }^{24}$ Kerala has the highest life expectancy in the country and the lowest values for maternal and infant mortality rates in India. The state also has much lower proportion of population under the poverty line $(7.1 \%)$ compared with the national average $(21.9 \%)$. The scenario reported from here probably reflects the future perspective for most Indian states related to CAD prevention. ${ }^{24}$

Our study reported that compliance to individual secondary prevention targets aimed at CAD are adopted differentially in the study population. Smoking cessation showed excellent compliance followed by moderate compliance to BMI target, BP control and diabetes control. The compliance to $\mathrm{PA}$ requirements as well as LDL control paints a dismal picture with tremendous scope for improvement. The study suggests that regular

Table 2 Overall compliance to secondary prevention targets

\begin{tabular}{|c|c|c|c|}
\hline \multirow[b]{2}{*}{ Target components } & \multicolumn{3}{|c|}{ Overall compliance with $95 \% \mathrm{Cl}$} \\
\hline & $\mathbf{n}$ & Compliance (\%) & $95 \% \mathrm{Cl}$ \\
\hline Smoking cessation & $456^{\star}$ & $428(93.86)$ & 91.66 to 96.06 \\
\hline Blood pressure control (<140/90 mm Hg) & 1206 & $785(65.11)$ & 62.42 to 67.80 \\
\hline LDL level (<70 mg/dL) & $810 \dagger$ & $296(36.50)$ & 33.18 to 39.82 \\
\hline PA level (150 min moderate to severe PA/week) & 1206 & $473(39.22)$ & 36.46 to 41.98 \\
\hline
\end{tabular}

*Total smokers.at the time of primary event/diagnosis.

†LDL tested participants.

$\ddagger \mathrm{HbA} 1 \mathrm{c}$ tested participants.

BMI, body mass index; HbA1c, glycated haemoglobin; LDL, low density lipoprotein; PA, physical activity. 
Table 3 Proportion of patients on cardiovascular drug therapy

\begin{tabular}{lcrc}
\hline Cardiovascular medicine & Overall n (\%) & Males n (\%) & Females n (\%) \\
\hline Antiplatelets/anticoagulants & $1158(96.0)$ & $844(96)$ & $314(96)$ \\
Lipid-lowering drugs (Statins) & $1078(89.4)$ & $790(89.9)$ & $288(88.1)$ \\
Renin angiotensin aldosterone system inhibitors & $455(37.7)$ & $309(30.2)$ & $144(44.1)$ \\
Calcium channel blockers & $215(17.8)$ & $145(16.5)$ & $70(21.4)$ \\
Diuretics & $147(12.2)$ & $99(11.3)$ & $48(14.7)$ \\
Betablockers & $822(68.2)$ & $610(69.5)$ & $212(64.8)$ \\
Insulin* & $134(22)$ & $94(21.76)$ & $40(22.59)$ \\
\hline Oral hypoglycaemic agents* & $495(81.28)$ & $353(81.71)$ & $142(80.23)$ \\
\hline
\end{tabular}

*Data from 609 patients with diabetes only.

screening for LDL control is suboptimal. The monitoring of diabetic control among those with diabetes is also suboptimal despite the fact that one in two patients in the study has diabetes.

Several registries/studies related to secondary prevention of CAD across the globe allow us to critically examine the findings of the current study with a global perspective. ${ }^{45-28}$

Among the secondary prevention strategies, the best response seems to be in adiposity management for the current study. Among study patients, two out of three have kept their BMI in the recommended range. This is much higher compared with the Euroaspire series of surveys (2001-2018) where only one in five could achieve this target. ${ }^{13172930}$ This difference appears larger even after accounting for the different cutoffs $\left(20-25 \mathrm{~kg} / \mathrm{m}^{2} \mathrm{vs}\right.$ $18.5-25 \mathrm{~kg} / \mathrm{m}^{2}$ ) used for BMI in the two studies. A probable reason for the good compliance to BMI-based target could be the fact that India has lower mean BMI levels when compared with European countries. ${ }^{31}$ Currently, India is at the bottom decile of mean BMI levels for both men and women. ${ }^{31}$

The majority of patients abstained from smoking $(97.7 \%)$ in the study population which appears to be higher compared with $81 \%$ reported by Euroaspire V. ${ }^{17}$ The state of Kerala has a much lower smoking prevalence $(12.7 \%)$ when compared with the national average (28.6\%) which may be the reason for the excellent compliance to the smoking cessation target. ${ }^{24}$

The figures for LDL control appear to be better in our study compared with Euroaspire V (36.5\% vs 29\%). Statin therapy is the most significant independent predictor for achieving LDL treatment target in patients with CAD or CVD. ${ }^{28}$ Other significant predictors include age, history of $\mathrm{CAD}$, diabetes, blood pressure and sex. ${ }^{28} \mathrm{~A}$ worrying aspect noted in the current study is the low prevalence of regular screening related to LDL levels in all patients in the current study. Similar low adoption of regular LDL screening among patients with CAD was reported from Finland. ${ }^{32}$

Regular screening for adequate diabetic control among patients with $\mathrm{CAD}$ and with diabetes appears to be on the lower side $(60 \%)$ in the current study. Among those who were screened, only one in two demonstrated adequate diabetic control ( $\mathrm{HbA1C}<7 \%)$ which is similar to that reported by Euroaspire V. The risk for coronary events among those with diabetes are known to decrease with older age.$^{33}$ Higher HbA1C levels are known to be associated with higher cardiovascular events and cardiovascular mortality in patients with CAD and with diabetes. ${ }^{34}$

Our study shows a higher burden of diabetes $(50.5 \%)$ compared with data from Euroaspire V survey (29\%), REACH registry (36.1\%), Atherogene study (17.2\%) as well as the CLARIFY registry (29.1\%). ${ }^{45}{ }^{2735}$ High prevalence of diabetes among those with CAD were reported earlier from Indian (42.9\%) and Malaysian (43.24\%) components of the CLARIFY registry as well as from the CADY registry (44.23\%) from India. ${ }^{26} 3536$

The management of diabetes is suboptimal in the continent. Patients with diabetes in India have a mean HbAlc at much higher levels than suggested by international guidelines. ${ }^{37}$ In addition, approximately half of those with diabetes in India remain undetected and a significant proportion of them have complications at the time of diagnosis of diabetes. These two factors may probably play a role in the poor compliance to glycaemic control in Indian patients with $\mathrm{CAD} .{ }^{37} \mathrm{~A}$ high prevalence of diabetes in combination with poor diabetic control among patients with $\mathrm{CAD}$ in India could probably be a lethal combination. This needs to be addressed for improvements in outcomes for patients with CAD with diabetes in India.

In terms of blood pressure control, the current study reports higher compliance $(65.1 \%)$ compared with data from REACH registry $(58.1 \%)$ as well as Euroaspire V $(58 \%) .{ }^{1725}$ The compliance appears to be better than the Indian component of the CLARIFY registry which showed good BP control in $59.5 \%$ of subjects. ${ }^{35}$ The fact that one in three patients with CAD have BP levels in the undesired range is a matter of concern. The same suggests that more needs to be done in improving the blood pressure control of patients with CAD.

Compliance to PA enhancement in the current study (39.22\%) appears to be much lower than that required for optimal secondary prevention of CAD. A recent 


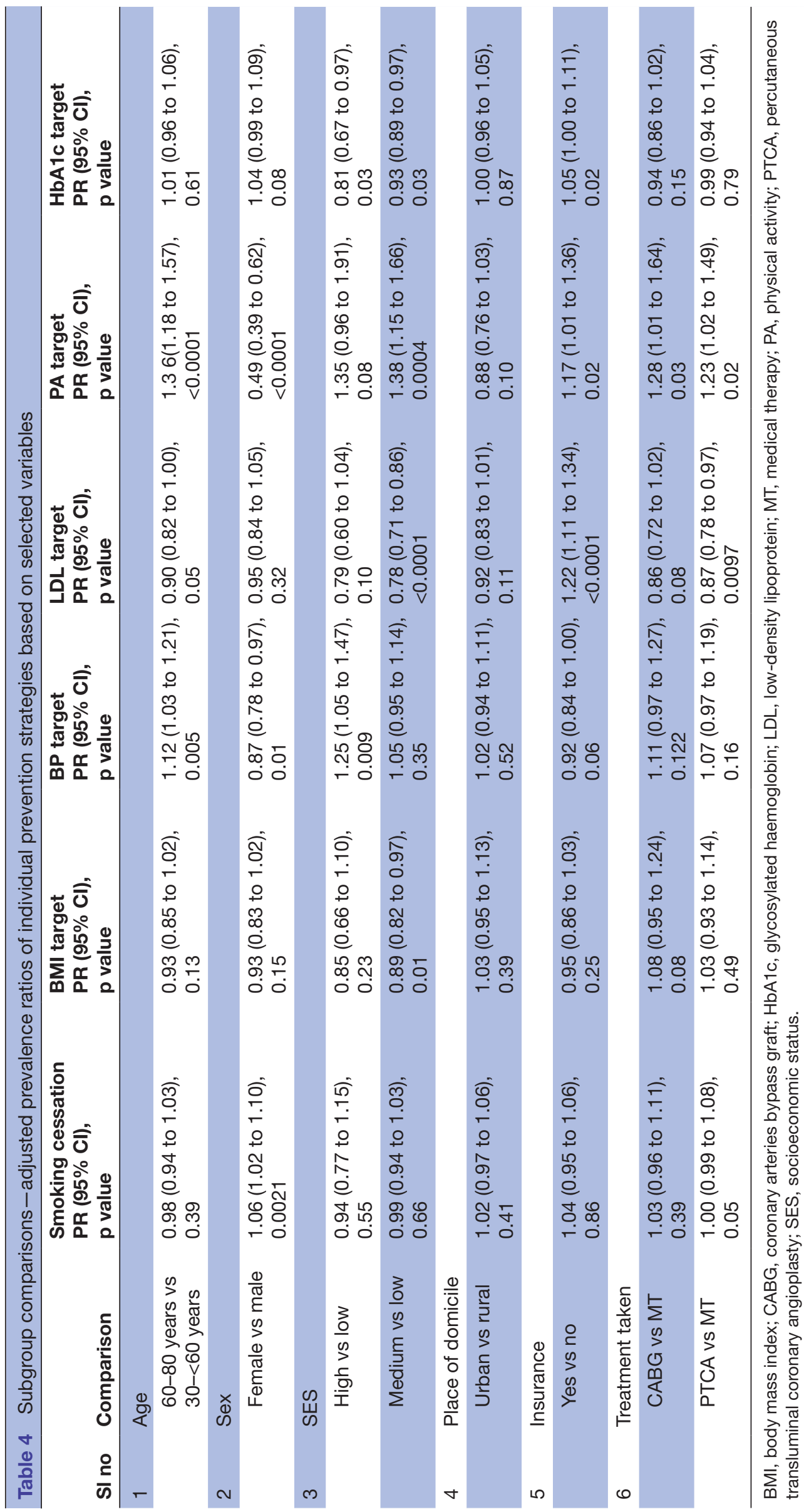


meta-analysis that included patients who have had myocardial infarction (MI), coronary arteries bypass graft, percutaneous transluminal coronary angioplasty, angina pectoris or CAD reported that exercise programmes are effective in reducing overall and cardiovascular-specific mortality as well as hospital admissions in shorter term follow-up. ${ }^{38}$ PA plays an important role in secondary prevention of cardiovascular diseases by reducing the impact of the disease, slowing its progress and preventing recurrence ${ }^{39}$ Unfortunately, majority of patients with CAD do not benefit from cardiac rehabilitation programmes and these patients are less probable to be physically active. ${ }^{40} 41$ A recent multicentre study that examined PA levels in India reported that $<10 \%$ of adults aged 20-80 years engage in recreational activity. ${ }^{42}$ This background level of sedentariness could be a reason for the low compliance to PA among patients with CAD in India.

The profile of cardiovascular and antidiabetic drug use seen in our study appears to be different from that reported by Euroaspire V data. ${ }^{17}$ Our study reported a higher use of antiplatelets (96\% vs $93 \%)$ and statins $(89.4 \%$ vs $80 \%)$ along with a lower use of RAAS $(37.7 \%$ vs $75 \%)$ as well as betablockers ( $68.2 \%$ vs $81 \%)$ in comparison to Euroaspire V data. ${ }^{17}$

The subgroup comparisons show mixed signals. Those insured showed good compliance to LDL control in comparison to uninsured patients. Women showed better compliance to smoking cessation and poor compliance to PA targets when compared with men. Compared with low SES, middle SES group had better PA compliance but poor LDL control. The type of treatment as well as area of domicile appeared to have no significant association with compliance to any of the six secondary prevention strategies as per the current study.

Secondary prevention of CAD in a low-resource setting with a high prevalence of CAD like that seen for India and Kerala in particular is a difficult task that requires additional efforts. The state of Kerala has comparable CAD prevalence to that of the national average as per a recent systematic review. ${ }^{18}{ }^{43}$ The public expenditure on health as percentage of gross domestic product (GDP) is at a low of $0.93 \%$ for Kerala which is even smaller than the national average at $1.02 \%$. Only Bangladesh has a lower expenditure proportion than India in this aspect across all nations in the Southeast Asian region. ${ }^{24}$

Only $37.2 \%$ of population has some form of insurance in India which is comparable to the level reported in the current study (36.2\%). Approximately $80 \%$ of those insured in India are covered by public health insurance schemes with limited coverage. The insurance coverage for patients with CAD in this study appears to be higher than that reported by an earlier study (29\%) in 2012 suggesting a slow improvement in insurance coverage with time. ${ }^{44}$

Secondary prevention of CAD in a low-resource setting like India is ridden with challenging scenarios. ${ }^{45}$ The impact of resource limitations is reflected as delayed diagnosis, poor quality treatment and poor compliance to primary and secondary prevention strategies. ${ }^{45}$ The quality of secondary prevention of CAD in India is reported to be suboptimal. ${ }^{46}$

The impact of these deficiencies in the care of CAD are clearly evident in the years of life lost (YLL) to CVD in India. There is a rising trend of YLL due to CVD in the last three decades in India suggesting a worsening of the impact of CVD from a social perspective. ${ }^{47}$ The current YLL from CVD in India is relatively higher compared with those reported from developed nations. ${ }^{47}$ In addition, the mortality from IHDs in India are more than twice the rate in North America and Western Europe. ${ }^{48}$ These two reported findings emphasise the importance of secondary prevention in the country. It has been reported that the proper implementation of secondary prevention therapies can reduce current mortality by $20 \%-30 \%$ among patients with established CAD in India. ${ }^{45}$ The same approach can also help in reducing the morbidity from CAD in the country. ${ }^{45}$

Strengths of the current study include a large sample size, high response rate among responders and information related to several confounders. The limitations include limited geographic/ethnic variation among study subjects. In the study, study personnel were chosen to administer the questionnaire due to the need for capturing technical data from diagnostic reports, discharge summaries and prescriptions. We acknowledge that administration of questionnaire by study personnel might have resulted in a social desirability bias. The ESC guidelines exclude never smokers in the compliance related to smoking cessation and the same is applicable only to those smoking at the time of diagnosis/primary event. We excluded the never smokers from the subgroup analysis for smoking cessation in compliance with the guidelines.

\section{CONCLUSIONS}

Secondary prevention of CAD wholly depends on the management of major CVD risk factors such as adiposity, high blood pressure, smoking, diabetes, LDL cholesterol as well as enhancement of PA. Poor adoption of secondary prevention strategies among low-resource settings has the potential to attenuate our efforts aimed at tackling the global burden of CAD. Intervention studies that focus on improving the overall compliance to secondary prevention options could probably result in better compliance and improved outcome profile among patients with CAD from low-resource settings like India.

\section{Author affiliations}

${ }^{1}$ Departments of Health Sciences Research \& Cardiology, Amrita Institute of Medical Sciences \& Research Centre, Amrita Vishwa Vidyapeetham, Kochi, India

${ }^{2}$ Department of Health Sciences Research, Amrita Institute of Medical Sciences \& Research Centre, Amrita Vishwa Vidyapeetham, Kochi, India

${ }^{3}$ Pediatrics, Pediatric Cardiology \& Public Health Research, Amrita Institute of Medical Sciences \& Research Centre, Amrita Vishwa Vidyapeetham, Kochi, India 
${ }^{4}$ Department of Cardiology, Amrita Institute of Medical Sciences \& Research Centre, Amrita Vishwa Vidyapeetham, Kochi, India

${ }^{5}$ Department of Cardiology, Lisie Hospital, Kochi, India

${ }^{6} \mathrm{GH}$ Ernakulam, Ernakulam, India

${ }^{7}$ Department of Epidemiology, Dalla Lana School of Public Health, University of Toronto, Toronto, Ontario, Canada

\section{Twitter Manu Raj @doc_manu}

Acknowledgements The authors thank Dr Ancy Paul, Dr Riya Kuriakose, Mr Vishnu Sugathan, Mr Vishak, Mrs Sonu KS, Mrs Neethu Raj and Dr ApsyVarky for data collection and patient care.

Contributors RS conceived the idea and is the guarantor of the study. RS, DV and MR supervised the collection of the data. RS and MR participated in data collection. RS, MR and CK carried out data management. RS, MR and CK analysed the data. RS, DV and MR drafted the manuscript. RS, DV, MR, RT, MV, JA, PT, VG and CK read the drafts and provided feedback. All authors read and approved the final manuscript.

Funding All study expenses were covered by the principal investigator (RS).

Competing interests None declared.

Patient and public involvement Patients and/or the public were involved in the design, or conduct, or reporting or dissemination plans of this research. Refer to the Methods section for further details.

Patient consent for publication Not required.

Provenance and peer review Not commissioned; externally peer reviewed.

Data availability statement Data are available upon reasonable request. Deidentified raw data can be made available for research-related request after institutional clearance.

Open access This is an open access article distributed in accordance with the Creative Commons Attribution Non Commercial (CC BY-NC 4.0) license, which permits others to distribute, remix, adapt, build upon this work non-commercially, and license their derivative works on different terms, provided the original work is properly cited, appropriate credit is given, any changes made indicated, and the use is non-commercial. See: http://creativecommons.org/licenses/by-nc/4.0/.

\section{ORCID iD}

Remya Sudevan http://orcid.org/0000-0002-1347-0277

\section{REFERENCES}

1 Prabhakaran D, Yusuf S. Cardiovascular disease in India: lessons learnt \& challenges ahead. Indian J Med Res 2010;132:529-30.

2 GBD 2013 Mortality and Causes of Death Collaborators. Global, regional, and national age-sex specific all-cause and causespecific mortality for 240 causes of death, 1990-2013: a systematic analysis for the global burden of disease study 2013. Lancet 2015;385:117-71.

3 GBD 2013 Mortality and Causes of Death Collaborators. Global, regional, and national age-sex specific all-cause and causespecific mortality for 240 causes of death, 1990-2013: a systematic analysis for the global burden of disease study 2013. Lancet 2015;385:1151-210.

4 KauL U, Natrajan S, Dalal J, et al. Prevalence and control of cardiovascular risk factors in stable coronary artery outpatients in India compared with the rest of the world: an analysis from international clarify registry. Indian Heart J 2017;69:447-52.

5 Nag T, Ghosh A. Cardiovascular disease risk factors in Asian Indian population: A systematic review. J Cardiovasc Dis Res 2013;4:222-8.

6 Balarajan R. Ethnic differences in mortality from ischaemic heart disease and cerebrovascular disease in England and Wales. BMJ 1991;302:560-4.

7 Enas E, Garg A, Davidson M, et al. Coronary heart disease and its risk factors in first generation immigrant Asian Indians to the United States of America. Indian Heart J 1995;48:343-53.

8 De Bacquer D, Dallongeville J, Kotseva K, et al. Residual risk of cardiovascular mortality in patients with coronary heart disease: the EUROASPIRE risk categories. Int J Cardiol 2013;168:910-4.

9 Hall SL, Lorenc T. Secondary prevention of coronary artery disease. Am Fam Physician 2010;81:289-96.

10 Smith SC, Benjamin EJ, Bonow RO, et al. AHAVACCF secondary prevention and risk reduction therapy for patients with coronary and other atherosclerotic vascular disease: 2011 update: a guideline from the American heart association and American college of cardiology foundation endorsed by the world heart Federation and the preventive cardiovascular nurses association. J Am Coll Cardiol 2011;58:2432-46.

11 Authors/Task Force Members, Piepoli MF, Hoes AW, et al. 2016 European guidelines on cardiovascular disease prevention in clinical practice: the sixth joint task force of the European society of cardiology and other societies on cardiovascular disease prevention in clinical practice (constituted by representatives of 10 societies and by invited experts): developed with the special contribution of the European association for cardiovascular prevention \& rehabilitation (EACPR). Eur J Prev Cardiol 2016;23:NP1-96.

12 Kotseva K, Wood D, De Backer G, et al. EUROASPIRE III: a survey on the lifestyle, risk factors and use of cardioprotective drug therapies in coronary patients from 22 European countries. Eur J Cardiovasc Prev Rehabil 2009;16:121-37.

13 Yusuf S, Islam S, Chow CK, et al. Use of secondary prevention drugs for cardiovascular disease in the community in high-income, middleincome, and low-income countries (the pure study): a prospective epidemiological survey. Lancet 2011;378:1231-43.

14 Gupta R, Islam S, Mony P, et al. Socioeconomic factors and use of secondary preventive therapies for cardiovascular diseases in South Asia: the pure study. Eur J Prev Cardiol 2015;22:1261-71.

15 Chen Y, Li L, Zhang Q, et al. Use of drug treatment for secondary prevention of cardiovascular disease in urban and rural communities of China: China Kadoorie Biobank study of 0.5 million people. Int $J$ Cardiol 2014;172:88-95.

16 Mendis S, Abegunde D, Yusuf S, et al. Who study on prevention of recurrences of myocardial infarction and stroke (WHO-PREMISE). Bull World Health Organ 2005;83:820-9.

17 Kotseva K, De Backer G, De Bacquer D, et al. Lifestyle and impact on cardiovascular risk factor control in coronary patients across 27 countries: results from the European Society of cardiology ESCEORP EUROASPIRE V registry. Eur J Prev Cardiol 2019;26:824-35.

18 Krishnan MN, Zachariah G, Venugopal K, et al. Prevalence of coronary artery disease and its risk factors in Kerala, South India: a community-based cross-sectional study. BMC Cardiovasc Disord 2016;16:12

19 Kotseva K, Wood D, De Bacquer D, et al. EUROASPIRE IV: a European Society of cardiology survey on the lifestyle, risk factor and therapeutic management of coronary patients from 24 European countries. Eur J Prev Cardiol 2016;23:636-48.

20 Perk J, De Backer G, Gohlke H, et al. European guidelines on cardiovascular disease prevention in clinical practice (version 2012). The fifth joint task force of the European society of cardiology and other societies on cardiovascular disease prevention in clinical practice. Developed with the special contribution of the European association for cardiovascular prevention \& rehabilitation (EACPR). Eur Heart J 2012;33:1635-701.

21 Sheridan PJ, Crossman DC. Critical review of unstable angina and non-ST elevation myocardial infarction. Postgrad Med J 2002;78:717-26.

22 WHO Consultation on Obesity (1999: Geneva, Switzerland) \& World Health Organization. Obesity: preventing and managing the global epidemic: report of a who consultation. World Health organization, 2000. Available: https://apps.who.int/iris/handle/10665/42330

23 Saleem SM. Modified Kuppuswamy scale updated for year 2018. Indian J Res 2018;7:6-7.

24 Government of India National health profile 2019. Central bureau of health intelligence. Directorate General of Health Services. Ministry of Health \& Family Welfare, Government of India, WHO collaborating centre on Family of International Classification, 2020. Available: https://www.cbhidghs.gov.in/index8.php

25 Sabouret P, Cacoub P, Dallongeville J, et al. Reach: International prospective observational registry in patients at risk of atherothrombotic events. results for the French arm at baseline and one year. Arch Cardiovasc Dis 2008;101:81-8.

26 lyengar SS, Gupta R, Ravi S, et al. Premature coronary artery disease in India: coronary artery disease in the young (CADY) registry. Indian Heart J 2017;69:211-6.

27 Zengin E, Bickel C, Schnabel RB, et al. Risk factors of coronary artery disease in secondary prevention-results from the atheroGenestudy. PLoS One 2015;10:8.

28 Ho L-T, Yin W-H, Chuang S-Y, et al. Determinants for achieving the LDL-C target of lipid control for secondary prevention of cardiovascular events in Taiwan. PLoS One 2015;10:10.

29 EUROASPIRE II Study Group. Lifestyle and risk factor management and use of drug therapies in coronary patients from 15 countries; principal results from EUROASPIRE II Euro heart survey programme. Eur Heart J 2001;22:554-72. 
30 Kotseva K, Wood D, De Bacquer D, et al. EUROASPIRE IV: a European Society of cardiology survey on the lifestyle, risk factor and therapeutic management of coronary patients from 24 European countries. Eur J Prev Cardiol 2016;23:636-48.

31 NCD, RisC. Risk factor collaboration database, 2020. Available: http://ncdrisc.org/bmi-mean-ranking.html

32 Repo T, Tykkyläinen M, Mustonen J, et al. Outcomes of secondary prevention among coronary heart disease patients in a high-risk region in Finland. Int J Environ Res Public Health 2018;15:724.

33 Tancredi M, Rosengren A, Svensson A-M, et al. Glycaemic control and excess risk of major coronary events in patients with type 2 diabetes: a population-based study. Open Heart 2019;6:e000967.

34 Cavero-Redondo I, Peleteiro B, Álvarez-Bueno C, et al. Glycated haemoglobin $\mathrm{A} 1 \mathrm{C}$ as a risk factor of cardiovascular outcomes and all-cause mortality in diabetic and non-diabetic populations: a systematic review and meta-analysis. BMJ Open 2017;7:e015949.

35 KauL U, Natrajan S, Dalal J, et al. Prevalence and control of cardiovascular risk factors in stable coronary artery outpatients in India compared with the rest of the world: an analysis from international clarify registry. Indian Heart J 2017;69:447-52.

36 Chee $\mathrm{KH}$, Choo GH, Jamaluddin ANB, et al. Clinical characteristics, treatment and 2-year outcomes in Malaysian and Bruneian patients with stable coronary artery within the worldwide clarify registry. Med J Malaysia 2017;72:282-5.

37 Joshi SR. Diabetes care in India. Ann Glob Health 2016;81:830-8.

38 Heran BS, Chen JM, Ebrahim S, et al. Exercise-based cardiac rehabilitation for coronary heart disease. Cochrane Database Syst Rev 2011;7:CD001800.

39 Alves AJ, Viana JL, Cavalcante SL, et al. Physical activity in primary and secondary prevention of cardiovascular disease: overview updated. World J Cardiol 2016;8:575-83.
40 Bjarnason-Wehrens B, McGee H, Zwisler A-D, et al. Cardiac rehabilitation in Europe: results from the European cardiac rehabilitation inventory survey. Eur J Cardiovasc Prev Rehabil 2010;17:410-8.

41 Stewart R, Held C, Brown R, et al. Physical activity in patients with stable coronary heart disease: an international perspective. Eur Heart J 2013;34:3286-93.

42 Anjana RM, Pradeepa R, Das AK, et al. Physical activity and inactivity patterns in India - results from the ICMR-INDIAB study (Phase-1) [ICMR-INDIAB-5]. Int J Behav Nutr Phys Act 2014;11:26.

43 Rao M, Xavier D, Devi P, et al. Prevalence, treatments and outcomes of coronary artery disease in Indians: a systematic review. Indian Heart J 2015;67:302-10.

44 Daivadanam M, Thankappan KR, Sarma PS, et al. Catastrophic health expenditure \& coping strategies associated with acute coronary syndrome in Kerala, India. Indian J Med Res 2012;136:585-92.

45 Gupta R, Khedar RS, Gaur K, et al. Low quality cardiovascular care is important coronary risk factor in India. Indian Heart J 2018;70 Suppl 3:S419-30.

46 Prabhakaran D, Jeemon P, Roy A. Cardiovascular diseases in India: current epidemiology and future directions. Circulation 2016;133:1605-20.

47 Global Burden of Disease Study. Health data, 2010. Available: http:// www.healthdata.org/sites/default/files/files/country_profiles/GBD/ inme_gbd_country_report_india.pdf

48 Roth GA, Johnson C, Abajobir A, et al. Global, regional, and national burden of cardiovascular diseases for 10 causes, 1990 to 2015. J Am Coll Cardiol 2017;70:1-25. 